Original article

\title{
Lung function and respiratory symptoms among mine workers in the Eastern part of Iran
}

\author{
Abdollah Gholami ${ }^{1}$, Javad Sajedifar ${ }^{2}$, Behzad Fouladi Dehaghi ${ }^{3}$, Leila Ibrahimi Gavamabadi ${ }^{4}$, \\ Gholamheidar Teimori Boghsani ${ }^{5}$, Abdoljalil Tazeroudi ${ }^{6}$, Mohsen Attar ${ }^{5}$ \\ ${ }^{1}$ Birjand University of Medical Sciences, Birjand, Iran \\ ${ }^{2}$ Neyshabur University of Medical Sciences, Neyshabur, Iran \\ ${ }^{3}$ Ahvaz Jundishapur University of Medical Sciences, Ahvaz, Iran \\ ${ }^{4}$ Islamic Azad University, Ahvaz Branch, Ahvaz, Iran \\ ${ }^{5}$ Torbat Heydariyeh University of Medical Sciences, Torbat Heydariyeh, Iran \\ ${ }^{6}$ Iranshahr University of Medical Sciences, Iranshahr, Iran
}

Received 24 December 2017, Revised 6 March 2018, Accepted 22 June 2018

C 2017, Gholami A., Sajedifar J., Fouladi Dehaghi B., Ibrahimi Gavamabadi L., Teimori Boghsani G., Tazeroudi A., Attar M.

(C) 2017, Russian Open Medical Journal

Abstract: Background - Workers in the mineral industries are exposed to airborne dust and its occupational exposure can cause respiratory disorders. The aim of this study was to determine the lung function and respiratory symptoms of workers exposed to mineral dust in the Eastern part of Iran.

Material and Methods - This cross-sectional study was conducted on 156 workers in kaolin mine, gold mine, quarry, and stone cutting workshops as a dust exposed group and 48 administrative personnel in these sections as an unexposed group. After the general medical examination and completion of the demographic questionnaire, workers' pulmonary function test was performed for each person using a spirometer according to the American Thoracic Society standards. Finally, data analysis was performed using Tukey's post hoc and chisquared tests.

Results - The mean age in the exposed group to dust and control group were $33.8 \pm 7.9$ and $36.7 \pm 8.0$ years (data are presented as mean with standard deviation), weight $-75.1 \pm 13.0$ and $75.0 \pm 11.2 \mathrm{~kg}$, height $-173.2 \pm 6.8$ and $173.1 \pm 6.3 \mathrm{~cm}$, and work experience $-9.1 \pm 4.6$ and $8.4 \pm 5.3$ years, respectively. There was no significant difference between the working groups in the kaolin, gold, quarry, and stone cutting sections and the control group on the demographic variables. The mean value of the lung function parameters was lower in different working groups than in the control group. Significant differences were observed between the two groups in forced vital capacity and forced expiratory volume in 1 second parameters $(P<0.05)$; however, there was no significant difference between them in peak expiratory flow and forced expiratory flow $25-75 \%(P>0.05)$.

Conclusion - The results showed the exposed groups have significantly lower pulmonary function than the control group. Two out of four main pulmonary function variables showed reduce amounts in exposed groups.

Keywords: lung function, respiratory symptoms, mineral dust, workers.

Cite as Gholami A, Sajedifar J, Fouladi Dehaghi B, Ibrahimi Gavamabadi L, Teimori Boghsani G, Tazeroudi A, Attar M. Lung function and respiratory symptoms among mine workers in the Eastern part of Iran. Russian Open Medical Journal 2018; 7: e0306.

Correspondence to G. Teimori Boghsani. Address: Torbat Heydariyeh University of Medical Sciences, Razi Str., North Ferdosi av., Torbat Heydariyeh, Khorasan Razavi, Iran. Email: Teimorigh1@gmail.com. Tel: +985152226011.

\section{Introduction}

In the mineral industry, there are various operations such as extraction of mineral materials, crushing, screening, loading etc., which result in the exposure of workers to high concentrations of inhalable particulates. Exposure to inhalable dust can endanger the safety and health of workers [1]. Silica is the most abundant element in the earth's crust, which is a toxic substance to the human respiratory system [2].

According to previous studies, workers of various industries such as mining, sand and gravel mines, kaolin, pottery, construction, drilling, brick manufacturing, foundry, stone milling, stone cutting, Portland cement production, tile and ceramics, iron, and steel are potentially exposed to the silica dust particles which can seriously endanger their health $[3,4]$. The result of this detrimental factor is the emergence of numerous occupational lung diseases such as silicosis and other pulmonary lesions [5]. According to the National Institute for Occupational Safety and Health (NIOSH) estimate, more than 1.7 million U.S. workers are exposed to crystalline silica, and each year more than 250 of them die with silicosis [6, 7]. However, there is no clear profile of exposure to crystalline silica among the Iranian workforce in Iran [5].

Numerous epidemiological studies have shown the association between respiratory disorders and occupational exposure to dust [8]. The results of the study by Kakooe et al. showed that dust containing silica can reduce the pulmonary function parameters [9]. The study by Hochgatterer et al. showed that lung function 
decreases in the long term occupational exposure to mineral dust and worsens with smoking [2]. Isara et al. studied respiratory symptoms and functions among quarry workers in Edo state, Nigeria. Similarly, pulmonary function of exposed workers was studied with the main four indices: forced expiratory volume in 1 second (FEV1), forced vital capacity (FVC), FEV1/FVC ratio, and peak expiratory flow (PEF). They found out that chronic exposure to quarry dust is associated with respiratory symptoms and reduced lung function indices among quarry workers [10]. According to study by Draid et al. on quarry industry workers, lung function tests of FVC, FEV1, and PEF were significantly changed in exposed workers [11].

During the last two decades, mineral processing industries have greatly expanded in Iran, and the number of individuals working in this field has increased accordingly [12]. In developing countries including Iran, health and safety practices among mining workers are not well established. Therefore, Preventive and control measures can be effective in maintaining and improving workers' health $[5,13]$. On the other hand, the knowledge of the pulmonary capacities of workers in different industries is very important from the point of view of occupational health, because this can play a major role in the better evaluation of occupational conditions and prediction of control measures.

Considering that the health effects of breathing dust especially crystalline silica are of great importance, this study was conducted to determine the lung function and respiratory symptoms in the workers exposed to mineral dust in various industrial sectors in the Eastern part of Iran.

\section{Material and Methods}

This descriptive-analytic cross-sectional study was carried out on workers exposed to mineral dust in mineral industries such as the kaolin, gold, stone cutting, and quarry mines in Eastern part of Iran. The exposed groups were selected from workers of different parts including; drilling, crushing, mill and packing that had a history of exposure to dust, and those working in the office comprised the control group. The study population consisted of 204 participants (156 workers as the exposed groups and 48 workers as the control group).

The participants groups were matched in order to compare different working groups and according to the entering criteria, workers with more than 3 years of work experience in the workshops polluted with mineral dust were included in this study, and all the workers with recent problems such as pneumothorax, hemoptysis, recent abdominal or eye surgery, unstable cardiovascular and recent heart attack and also smokers were not included in the study.

The study was conducted in accordance with the Helsinki Declaration and its amendments, and all participants filled out and signed the informed consent form for entry into the study.

The demographic data including age, work experience, height, and weight were obtained using a designed questionnaire. Moreover, a respiratory symptoms questionnaire was filled out by participants. The questionnaire included information on respiratory status (chronic cough, wheezing, Shortness of breath, bronchitis, etc.), smoking habits, medical history, family history (including chronic respiratory diseases, asthma, and respiratory infections such as tuberculosis), type of occupation, and previous occupations (especially occupations that pose potential risk for respiratory diseases and could distort the results of this study).
To evaluate pulmonary function, spirometry testing was performed by a calibrated spirometer (Vitalograph 2120, ENNIS, Ireland) according to the American Thoracic Society (ATS) guidelines on the standardization of spirometry (2005). The percent predicted value mean for the pulmonary function parameters was calculated according to age, height, gender, and race using a spirometer.

In practice, the spirometry test was repeated 3 to 5 times to gain acceptable and repeatable results. The tests were done with the study participant seated and upright according to ATS 2005 criteria. The best result of maneuvers was the one used for interpretation. The evaluated spirometry variables were FVC, FEV1, FVC/FEV1 ratio, and PEF.

Data were shown as mean with standard deviation $-M \pm S D$, and frequency with percentage $-\mathrm{n}(\%)$. The statistical analysis was performed using SPSS (version 21, SPSS Inc., Chicago, IL, USA), descriptive statistics, Tukey's post hoc and Chi-squared tests. Kolmogorov-Smirnov test was done to check the normality distribution of variables. As the variables were normal, ANOVA test was used for analysis comparison of the different groups mean. A $\mathrm{P}$-value of less than $0.05(\mathrm{P}<0.05)$ was considered statistically significant.

\section{Results}

Age, weight, height and work experience of the exposed group to dust were $33.8 \pm 7.9$ years, $75.1 \pm 13.1 \mathrm{~kg}, 173.2 \pm 6.8 \mathrm{~cm}$, and $9.1 \pm 4.6$ years, respectively. Age, weight, height and work experience of the control group were $36.7 \pm 8.0$ years, $75.0 \pm 11.2 \mathrm{~kg}$, $173.1 \pm 6.3 \mathrm{~cm}$ and $8.4 \pm 5.3$ years, respectively. The demographic data of the participants is presented in Table 1. There was no significant difference in the demographic characteristics between the working groups and the control group $(P>0.05)$.

Table 2 shows the lung function parameters of the participants. The results of Tukey's post hoc test showed that there was a significant difference in FVC and FEV1 between the kaolin mine, gold mine, quarry, and cutting stone working groups and the control group $(P<0.05)$. There was no significant difference between the groups in PEF and forced expiratory flow $25-75 \%$ (FEF25-75\%) (P>0.05).

The results of respiratory symptoms questionnaires are presented in Table 3. The frequency of cough, wheeze, and dyspnea, were higher in kaolin working groups than the other working groups and the control group. The chi-squared test showed that there was no significant difference between different exposed groups and the control group in the mean value of the respiratory symptoms $(\mathrm{P}>0.05)$.

\section{Discussion}

Regarding the results of this study, lung function parameters and pulmonary capacity in the exposed groups were lower than the control group. It can be concluded that the workers in different workplaces are exposed to higher levels of mineral dust. Also, the lung function parameters of FVC and FEV1 showed a significant decrease in each exposed group compared with the control group. This was consistent with findings by Isara et al. [10] among workers exposed to quarry dust in Edo state, Nigeria and Draid et al. on quarry industry workers in Libya [11]. The same results were obtained by similar studies [14-16]. 
Table 1. Demographic characteristics of participants

\begin{tabular}{|c|c|c|c|c|c|c|}
\hline Variables & Kaolin $(n=70)$ & Gold mine $(n=51)$ & Quarry (n=23) & Stone cutting $(n=12)$ & Control ( $n=48)$ & P-value* \\
\hline Age, years & $38.3 \pm 6.9$ & $35.4 \pm 9.1$ & $35.4 \pm 7.3$ & $38.1 \pm 8.8$ & $36.7 \pm 8.0$ & 0.399 \\
\hline Weight, kg & $78.8 \pm 12.7$ & $69.7 \pm 13.2$ & $77.3 \pm 11.6$ & $70.3 \pm 10.1$ & $75.0 \pm 11.2$ & 0.584 \\
\hline Height, cm & $173.0 \pm 7.1$ & $173.0 \pm 7.4$ & $173.0 \pm 5.5$ & $169.0 \pm 6.3$ & $173.0 \pm 6.3$ & 0.233 \\
\hline Work experience, years & $10.5 \pm 5.2$ & $8.0 \pm 3.6$ & $8.0 \pm 3.3$ & $9.1 \pm 6.2$ & $8.5 \pm 5.3$ & 0.077 \\
\hline
\end{tabular}

Data are presented as mean with standard deviation $-\mathrm{M} \pm \mathrm{SD} .{ }^{*}$ One-way variance analysis test.

Table 2. Comparison of lung function parameters of different working groups and control group

\begin{tabular}{|c|c|c|c|c|}
\hline Parameters & Control group & Working groups & & P-value* \\
\hline \multirow[t]{4}{*}{ FVC, liters } & $4.12 \pm 0.49$ & Kaolin & $3.40 \pm 0.67$ & 0.001 \\
\hline & & Gold mine & $3.29 \pm 0.48$ & 0.001 \\
\hline & & Stone cutting & $3.32 \pm 0.82$ & 0.004 \\
\hline & & Quarry & $3.61 \pm 0.51$ & 0.018 \\
\hline \multirow[t]{4}{*}{$\mathrm{FEV}_{1}$, liters } & $4.88 \pm 0.54$ & Kaolin & $4.16 \pm 0.64$ & 0.001 \\
\hline & & Gold mine & $4.04 \pm 0.57$ & 0.001 \\
\hline & & Stone cutting & $4.05 \pm 0.97$ & 0.002 \\
\hline & & Quarry & $4.37 \pm 0.67$ & 0.007 \\
\hline \multirow[t]{4}{*}{ PEF, liters } & $5.67 \pm 8.31$ & Kaolin & $5.40 \pm 1.05$ & 0.811 \\
\hline & & Gold mine & $4.56 \pm 1.59$ & 0.258 \\
\hline & & Stone cutting & $4.81 \pm 1.33$ & 0.197 \\
\hline & & Quarry & $5.32 \pm 9.27$ & 0.750 \\
\hline \multirow[t]{4}{*}{ FEF25-75\%, liters } & $3.88 \pm 0.92$ & Kaolin & $3.37 \pm 1.19$ & 0.268 \\
\hline & & Gold mine & $2.91 \pm 1.26$ & 0.445 \\
\hline & & Stone cutting & $3.48 \pm 1.17$ & 0.870 \\
\hline & & Quarry & $3.65 \pm 0.87$ & 0.940 \\
\hline
\end{tabular}

Data are presented as mean with standard deviation - M \pm SD. * Tukey's HSD (honest significant difference) test.

Table 3. Frequency distribution of respiratory symptoms in different working groups and control group

\begin{tabular}{|c|c|c|c|c|c|c|c|}
\hline Respiratory symptoms & Kaolin $(n=70)$ & Gold mine $(n=51)$ & Quarry (n=23) & Stone cutting $(n=12)$ & Control $(n=48)$ & $\chi^{2}$ & $P$-value* \\
\hline Cough & $8(15.4)$ & $1(2.6)$ & $2(8.7)$ & $2(22.2)$ & $2(4.7)$ & 7.318 & 0.120 \\
\hline Phlegm & $1(1.9)$ & $2(5.3)$ & $1(4.3)$ & - & $2(4.7)$ & 1.222 & 0.874 \\
\hline Wheeze & $5(9.6)$ & $3(7.9)$ & $3(13)$ & $2(22.2)$ & $1(2.3)$ & 5.006 & 0.287 \\
\hline Dyspnea & $6(11.5)$ & - & $1(4.3)$ & $1(11.1)$ & $1(2.3)$ & 7.354 & 0.118 \\
\hline
\end{tabular}

Data are presented as frequency with percentage $-\mathrm{n}(\%){ }^{*} \chi 2$, chi-squared test (comparison between exposure groups and control group).

The study indicated that the FVC and FEV1 values in the dust exposed groups were significantly reduced, and considering that there was no significant difference in the variables affecting the spirometry (gender, age, height, weight, work experience), this reduction could be attributed to the dust in the workplace.

In addition, there was no significant difference between the exposed groups and control group in PEF and FEF25-75\% variables, but PEF and FEF25-75\% parameters showed a significant difference between exposed groups. This can be affected by small and limited sample size. These results concur with other studies such as Kakooi et al. and Draid et al. [9, 11].

The results of the respiratory symptoms showed no significant difference between exposed and control groups. Our experiments are consistent with previous study [10]. In contrast to this report, some other literatures are available [17-19]. However, notably irritant cough in kaolin workers was higher than other workers, which is similarly stated by Aghilinejad et al. and Lemle et al. [20, 21].

These health effects of dust exposure are widely recognized, however, its exposure continues to take place globally. There are few control measures in the developing countries including Iran, especially in the mining workplaces [22].

\section{Conclusion}

The results of this study have demonstrated that exposure to dust in four above-mentioned industries has a detrimental role in respiratory function. In addition, the exposed groups have significantly lower pulmonary function than the control group. Two out of four main pulmonary function variables showed reduce amounts in exposed groups. The result of this study can be regarded as a helpful guide for regulatory authorities to provide wider spectrum supervision for such these industries.

\section{Limitations}

This is one of the limitations of this study that it relied on the questionnaire to estimate the respiratory symptoms in order to collect data from participants. It may be resulted in bias. Also, dust air sampling was not used to quantify dust exposure and compare the concentration of respirable dust in both the office and working units of the mineral industries. In addition to this, it is suggested that other pulmonary tests such as chest radiography be done and compared with the results of the previous ones to further corroborate the findings. 


\section{Ethical approval}

All procedures performed in studies involving human participants were in accordance with the ethical standards of the Torbat Heydariyeh University of Medical Sciences (Iran) and with the 1964 Helsinki declaration and its later amendments or comparable ethical standards.

\section{Conflict of interest}

The authors declare that they have no conflict of interests associated with this study.

\section{References}

1. Singh SK, Chowdhary G, Chhangani V, Purohit G. Quantification of reduction in forced vital capacity of sand stone quarry workers. Int $J$ Environ Res Public Health 2007; 4(4): 296-300. https://dx.doi.org/10.3390/ijerph200704040005.

2. Hochgatterer $\mathrm{K}$, Moshammer $\mathrm{H}$, Haluza D. Dust is in the air: effects of occupational exposure to mineral dust on lung function in a 9-year study. Lung 2013; 191(3): 257-263. https://doi.org/10.1007/s00408013-9463-7.

3. Rushton L. Chronic obstructive pulmonary disease and occupational exposure to silica. Rev Environ Health 2007; 22(4): 255-272. https://doi.org/10.1515/REVEH.2007.22.4.255.

4. Yassin A, Yebesi F, Tingle R. Occupational exposure to crystalline silica dust in the United States, 1988-2003. Environ Health Perspect 2005; 113(3): 255-260. https://dx.doi.org/10.1289\%2Fehp.7384.

5. Azari MR, Rokni M, Salehpour S, Mehrabi Y, Jafari MJ, Moaddeli AN, et al. Risk assessment of workers exposed to crystalline silica aerosols in the east zone of Tehran. Tanaffos 2009; 8(3): 43-50. http://www.tanaffosjournal.ir/files site/paperlist/r $284 \quad 1209191248$ 46.pdf.

6. Health UDo, Services H. Health effects of occupational exposure to respirable crystalline silica. Washington, DC: National Institute for Occupational Safety and Health, 2002.

7. Golbabaei F, Faghihi Zarandi A, Ebrahimnezhad P, Baneshi M, Mohseni Taklu H, Shokri A, et al. Assessment of occupational exposure to the respirable fraction of cement dust and crystalline silica. Journal of Health and Safety at Work 2012; 2(3): 17-28. Persian. http://jhsw.tums.ac.ir/article-1-5019-fa.html.

8. Bio F, Sadhra S, Jackson C, Burge P. Respiratory symptoms and lung function impairment in underground gold miners in Ghana. Ghana Med J 2007; 41(2): 38-47. https://www.ncbi.nlm.nih.gov/pubmed/17925840.

9. Kakooe H, Gholami A, Ghasemkhani M, Hossaini M. Survey of exposure to cement dust and its effect on respiratory function in workers of a cement complex. The Horizon of Medical Sciences 2012; 18(1): 60-65. http://hms.gmu.ac.ir/article-1-1062-en.html.

10. Isara AR, Adam VY, Aigbokhaode AQ, Alenoghena IO. Respiratory symptoms and ventilatory functions among quarry workers in Edo state, Nigeria. Pan Afr Med J 2016; 23: 212. https://doi.org/10.11604/pamj.2016.23.212.7640.

11. Draid MM, Ben-Elhaj KM, Ali AM, Schmid KK, Gibbs SG. Lung function impact from working in the pre-revolution Libyan quarry industry. Int $J$ Environ Res Public Health 2015; 12(5): 5006-5012. https://dx.doi.org/10.3390/ijerph120505006.

12. Dehghan F, Mohammadi S, Sadeghi Z, Attarchi M. Respiratory complaints and spirometric parameters in tile and ceramic factory workers. Tanaffos 2009; 8(4): 19-25. https://pdfs.semanticscholar.org/8583/f52be13a1f903311986e8bf7ea a47b67e3e8.pdf.

13. Kakooe H, Mousavi S, Panahi D, Azari RM, Hossaini M. Assessment of occupational exposure to total dust and crystalline silica in construction workers of metro, Tehran. Journal of Health and Safety at Work 2012; 1(1): 25-30. Persian. http://jhsw.tums.ac.ir/article-1-28fa.html.
14. Hassen KA, Ibrahim MS. Exposure to occupational dust and changes in pulmonary function among cobblestone paving workers of Jimma, Ethiopia. Revista Ambiente \& Água 2014; 9(1): 19-26. http://dx.doi.org/10.4136/ambi-agua.1227.

15. Zwain b. Lung function tests in Kufa cement factory. Al-Kufa Journal 1998; 2(1): 31-34.

16. Brüske I, Thiering E, Heinrich J, Huster KM, Nowak D. Respirable quartz dust exposure and airway obstruction: a systematic review and metaanalysis. Occup Environ Med 2014; 71(8): 583-589. http://dx.doi.org/10.1136/oemed-2013-101796.

17. Neghab M, Zadeh JH, Fakoorziba M. Respiratory toxicity of raw materials used in ceramic production. Ind Health 2009; 47(1): 64-69. https://doi.org/10.2486/indhealth.47.64.

18. Neghab M, Abedini R, Soltanzadeh A, Kashkooli Al, Ghayoomi S. Respiratory health of digging and excavating workers involved in constructing a dam in Fars province following occupational exposure to very high concentrations of dolomite dust. Iran Occupational Health 2012-2013; 9(4): 43-50. Persian. http://ioh.iums.ac.ir/article-1-976fa.html.

19. Mohammadi A, Tajdinan S. Survey of spirometric indices and prevalence of respiratory symptoms in the workers of a pipe mills. Jundishapur Journal of Health Sciences 2010; 2(3): 37-45.

20. Aghilinejad $M$, Jamaati $M$, Farshad AA. Prevalence of silicosis among workers in stone-cutter and silica powder production factories. Tanaffos 2006; 5(3): 31-36. http://www.tanaffosjournal.ir/files site/paperlist/r 4331209260849 29.pdf.

21. Lemle A, Lima PF, Cardoso A, Câmara MW, Marchiori E, Carnevalli L, et al. Respiratory Symptoms and Spirometric Tests of quarry workers in Rio de Janeiro. Rev Assoc Med Bras (1992) 1994; 40(1): 23-35. https://www.ncbi.nlm.nih.gov/pubmed/8061690.

22. Mohammadi H, Golbabaei F, Farhang Dehghan S, Normohammadi M. Occupational exposure assessment to crystalline silica in an insulator industry: Determination the risk of mortality from silicosis and lung cancer. Journal of Health and Safety at Work 2017; 7(1): 45-52. Persian. URL: http://jhsw.tums.ac.ir/article-1-5589-fa.html.

\section{Authors:}

Abdollah Gholami - Assistant Professor, Department of Occupational Health, School of Health, Birjand University of Medical Sciences, Birjand, Iran. https://orcid.org/0000-0001-5366-9048.

Javad Sajedifar - Instructor, Department of Occupational Health, School of Public Health, Neyshabur University of Medical Sciences, Neyshabur, Iran. https://orcid.org/0000-0001-8241-7747.

Behzad Fouladi Dehaghi - Assistant professor, Department of Occupational Health, Health Faculty, Ahvaz Jundishapur University of Medical Sciences, Ahvaz, Iran. https://orcid.org/0000-0003-3678-2713. Leila Ibrahimi Gavamabadi - Assistant Professor, Department of Environmental management-HSE, Islamic Azad University, Ahvaz Branch, Ahvaz, Iran. https://orcid.org/0000-0002-0790-8391.

Gholamheidar Teimori Boghsani - MSc, School of Health, Torbat Heydariyeh University of Medical Sciences, Torbat Heydariyeh, Iran. https://orcid.org/0000-0003-4908-4324.

Abdoljalil Tazeroudi - MSc, Department of Environmental Health Engineering, School of Public Health, Iranshahr University of Medical Sciences, Iranshahr, Iran. https://orcid.org/0000-0002-1077-6692.

Mohsen Attar - MSc, Torbat Heydariyeh University of Medical Sciences, Torbat Heydariyeh, Iran. https://orcid.org/0000-0002-6914-8164. 